\title{
Using Picture Stories and Mind Maps to Improve Narrative Ability of a CI Student
}

\author{
* Qurratulain Ershad, PhD Scholar \\ ** Dr. Sumaira Noreen, Assistant Professor
}

\begin{abstract}
This study aimed at investigating the impact of picture storytelling and Mind Maps as pre-writing tools for cochlear implanted student. Action research was conducted to improve cochlear implanted learner's narrative writing skills with the aid of picture storytelling and mind maps. Number cycles of action-research were carried out to teach narrative writing and mind mapping over a period of two months. Data were collected at three stages of the study which included: pre-intervention, intervention and post intervention. In the pre-intervention stage, data were collected by using prewriting samples. During the intervention stage, the data were collected through observations. In the post-intervention stage, data were collected by using two post writing samples. This strategy was developed on the assumption that while initially, the cochlear implanted learner would show difficulty in writing narratives and constructing mind maps but gradually the cochlear implanted learner would show less difficulty when the learner would become more acquainted with the strategies. The findings depicted positive outcomes in the writing ability of the participant. The result also showed a sound level of the effectiveness of picture storytelling and mind maps suggesting imperative need to incorporate them in educational settings in order to help cochlear implanted learners to write to their maximum potential.
\end{abstract}

\section{Introduction}

The following research is focused on the comprehension and assessment of the deficiencies that advance within oral language development for deaf/hard of hearing children. This is crucial to understand how such deficiencies can impact reading and writing of text and oral language progression. Development of comprehension and understanding text composition is essential for personal, social, and academic development of these children (Arfe, Nicolini, \& Pozzebon, 2014; Spencer, Barker, \& Tomblin, 2003), as enhancement of literacy skills remains a substantial challenge in both acquisition and advancement. Recent research indicates low literacy rate as being one of the major factors impacting this issue, with a number of research studies indicating that deaf/hard of hearing children face a number of challenges in terms of literacy and language development proficiency (Spencer et al., 2003).

Studies indicate that children with cochlear implants are not proficient in complex sentence formation. This is due to the fact that they fail to adequately apply parts of speech such as pronouns, determiners, conjunctions, verbs, adverbs, and prepositions with constructions (Spencer 2003). Incomprehensibility of narrative is a result of incorrect usage of conjunctions that are essential for combining and coordinating narrative clauses (Griffith, Ripich, \& Dastoli, 1990).

\section{Rationale}

Cochlear implant aids in hearing restoration and it is thus assumed that any betterment in spoken language should contribute to a comparative improvement in language skills such as writing. However, it is observed that even with implants, these children in comparison with their normalhearing peers have significantly poorer written expression and indicate an inability towards extensive narrative writing ( $\mathrm{Wu}, \mathrm{Ko}$, Chen, Tsou, \& Chao, 2015). This indicates that in addition to the implants another crucial aspect for improvement is rehabilitation. Since 2000, successful implants have been carried out in Pakistan with around $76 \%$ of the patients being residents of Lahore and Karachi but with only three rehabilitation therapists available to them. Amina Siddiqui of Ziauddin University announced a program teaching speech and language therapy to fill this lack of therapists (Dawn, 22 August, 2010).

\footnotetext{
* Institute of Education, Lahore College for Women University, Jail Road, Lahore. Pakistan Email: qurratulain.rehan@kinnaird.edu.pk

** Department of History, Lahore College for Women University, Jail Road, Lahore. Pakistan Email: sumnoreen2@yahoo.com
} 
With the scope and requirement of this issue in mind, the present research study aims at extensive exposure of the respondents to aspects of receptive language that include picture storytelling for vocabulary enhancement and improvement of syntactical structures. This will be in combination with mind-mapping that aids the cochlear implanted learner to associate thoughts with symbols instead of extraneous words, thereby enhancing learning outcomes through aiding the implanted learner with organization, expansion, and sequencing of ideas and concepts (Buzan, 2006).

Such a learning theory focuses on three core ways of information processing; representational, in which referential directly influences the verbal and non-verbal; verbal systems that are triggered through visual communication forms and vice-versa; and associative, in which text and images can affect a mental trigger. Through utilization of this theory a teacher can apply images/pictures, concreteness, imagery, and dual coding for maximization of student learning and making their writing more comprehensible and memorable.

Verbal associative techniques can have a significant impact on improvement of the organization and syntactic fluency of writing through utilization of techniques such as listing of relevant words to the topic being written about and practicing combined sentences.

Experiments based within Allan Paivio's dual coding theory were conducted by David in 1998 and focused on the effectiveness of incorporation of representational pictures within news items.

David (1998, p. 182) indicated that the core purpose of representation function was to increase the concreteness of the story, thereby providing a basic framework that could test the interactive association of concreteness and the facilitative role of the pictures. The study indicated a recall advantage for the visual representation (text/picture) and replicated experiments supported the hypothesis that concrete news was more effective than abstract news. Additionally, it was also noted that addition of a picture to a concrete news piece was more effective than adding on to an abstract news story.

\section{Objectives}

The objectives of the study were:

- $\quad$ to improve narratives of CI learner

- $\quad$ to reduce the grammatical errors made by the CI learner

- $\quad$ to write in a cohesive manner the series of events

- to learn the use of connectives

- to organize ideas in a logical manner

\section{Literature Review}

\section{Cochlear Implantation}

An electronic device known as the cochlear implant takes its name from the ear function that it replaces. The cochlear function is essential for transforming sound into neural messages; the implant however, does not enhance normal hearing but simulates natural sound in its relays in opposition to the sound amplification of conventional hearing aids. Documented research on cochlear implants has proven that they have a marked benefit on the speech perception and language development for children with severe/profound hearing loss (Blamey, Sarant, Paatsch, Barry, Bow, 2001; Moog, 2002; Nicholas \& Geers 2007).

\section{Cochlear Implanted and Writing Difficulties}

Writing is for both normal-hearing and hearing-impaired children, a task that is high in complexity. Deaf children in lieu of the reduced capability for hearing conversations and narrative discourses have problems in comprehending core ideas, event association, and connections between language structures (Schopmeyer, 2009).

The limited access to verbal information for deaf children can have an impact on their narrative capabilities as narrative skills have a development basis within the repeated exposure to stories of various types and forms (Berman, 1995; Snow \& Dickinson, 1990). This prerequisite anticipates the difficulty that deaf children experience while forming coherent narratives (Bamberg \& Damrad-Frye, 1991). Narrative writing can however be aided with use of picture stories that in turn can also provide shared experiences for the students in the classroom setting (Raimes, 1083, p. 28). 


\section{Writing Strategies \\ Picture Stories and Narrative Writing}

According to (Yoshinaga-Itano \& Downey, 1992), hard-of-hearing/deaf readers show difficulty in story-structure understanding. In a study by Alidoost (2014), picture stories indicated a positive effect on idea and organization in written narratives, with the experimental group showing increased capabilities for scenic transitions, organized narratives, and better expressions for sequential development.

\section{Mind Maps as Writing Strategies}

The visual imagery that is an essential aspect of Mind Maps can aid the implanted learner with sequential storage of information crucial to writing development. The use of Mind Maps can aid implanted learners through the visual presentation and colour coding of similar ideas and allowing ease of understanding for new concepts. This is due to the fact that introduction and organization of new concepts is simplified under this construct allowing connection and sequencing of information against prior knowledge and comparison and contrasting of two or more related aspects (Buzan, 2006).

\section{Methodology}

\section{Action Research}

The researcher's interest in writing and the effectiveness of picture storytelling and Mind Maps was based on a quest to find successful and pragmatic ways of helping cochlear implanted learner with writing difficulties. Children need to be taught a simple support system to structure their writing, thereby establishing a framework to help them 'write at length in a coherent and logical style' (Payne and Turner, 1999). The researcher's intent fitted well with an action research approach since it is a process, where the teacher plans, acts, observes and reflects for improvement of the teaching and learning process (Kemmis, McTaggart \& Retallick, 2004).

\section{Pre-intervention Stage}

In order to know student's view about, English language especially, narrative writing, difficulties, challenges faced by the participant, a semi-structured interview was conducted with participating student. To establish a base line for the first action plan and to have better view of the participant's writing level pre-test was conducted and analyzed.

\section{Intervention Stage}

The intervention stage consisted of a cyclical process of co-planning, teaching, observing and reflecting. The teacher and the therapist observed the researcher in some of the lessons; while in others, they were observed. The researcher and the teacher both reflected on the action and plan for the next lesson. This process continued for number of cycles. During the implementation phase, observations in form of field notes were recorded.

Cycle

In the each cycle a picture story was read aloud to the participant. The participant was encouraged to ask questions regarding story, new words, characters etc. The researcher explained parts of speech and difficult words use when required and clarified concepts and ideas student was not aware of. Based on the story read, the participant was taught and guided how to draw mind map of the read story. This helped the participant in organizing and structuring of her narrative writing. For first two cycles guided mind maps were constructed which eventually lead to independent mind mapping. The participant was asked to write a narrative with the help of the developed mind map. The five steps of the writing process namely prewriting, drafting, revising, editing and final draft were used for teaching narrative writing with the aid of picture story telling. The rationale of adopting this process writing model is based on the works of Flower and Hayes (1981). Once to the participant the picture story was read mind map was constructed then participant was asked to write a narrative text only with the help of the stages of writing. In the pre-writing stage they brainstormed the vocabulary (verb, noun, adjective, connectors, etc.). The participant used already constructed mind map to organize and plan the narrative writing: beginning, middle and ending. The participant also learned about the characters and their attributes, the setting, the plot, and the theme of the story. With all the information, participant was asked to proceed to compose the first draft. Once the participant has composed the first draft, the participant shared with the researcher, the teacher and the therapist, who provided appropriate feedback about general writing steps. After this stage was completed, the 
participant made corrections and rewrite the text as per the instructions of the researcher and the teacher. Finally, after going through the stages of writing the participant composed the final draft.

\section{Observation and Reflection Phases}

During the action phase, the researcher taught the participant by using picture storytelling and mind maps and closely observed student listening to picture story and constructing mind map. The critical friend and the therapist observed the researcher teacher's teaching. At the end of the class they reflected on what went well and what did not go well. Based on these observations and reflections the researcher planned the next cycle of action research. After every cycle narrative writing samples were collected.

\section{Post-Intervention}

During action research student's progress in learning was continuously monitored by the teacher, the therapist and the researcher. At the end of the intervention period post writing sample were collected analysed and compared with the pre free writing samples to determine the effectiveness of picture storytelling and mind maps.

\section{Analysis of the written Product}

The written narratives were analyzed on the basis of theme units called as t-units as stated by Hunt (as cited in Crosson \& Geers, 2001). The two coders analyzed the narratives into theme-units.

\section{Narrative Structure Score}

In order to analyze the narratives Labov and Waletzky's (1967) modified version of the high point anaylsis was used in the original form. The assessment was conducted in three parts: in the first part narrative structure score was calculated and there five maximum points for it. The second part consisted of two kinds of cohesion scores. The first type of cohesion score was based on the usage of conjunctions and carried maximum four points and the second type of cohesion score was about the reference specification which also carried maximum 4 points. Hence, the maximum score for total narrative ability was thirteen points.

The total length of the narratives was measured by counting the number of words. The finalized revised drafts were used for computing the total length of the narratives. A comparison between the two pre-tests and post-tests, with the same picture and picture story used for the pretest was drawn in accordance to the number of words for each picture; the number of words was linked to the number of pictures under consideration. Also, the grammatical errors' percentage was calculated. Errors committed in subject verb agreement or inflections, incorrect sequence of words, number of omitted function words, incorrect preposition or pronoun were calculated as grammatical errors. The content words percentage like verbs, common and proper nouns, and adjectives was computed for the measurement of lexical density.

\section{Reliability}

The two coders who were blind to the hearing level of the participants analyzed the written products. In case where there was some uncertainty, consensus was reached through discussion about grammatical errors, narrative ability and cohesion scores.

\section{Result}

Table 1

Pre-Test 1 \& II Results on all Measures of Written Language Ability in the CI Participant

\begin{tabular}{llccc}
\hline Measure: Written Product & \multicolumn{3}{l}{ CI Participant } & \\
& \multicolumn{2}{l}{ Post-Tests } & Mean & Range \\
& I & II & 27 & 4 \\
Total Number of words & 25 & 29 & 6 & 2 \\
Total Number of Sentences & 5 & 7 & 2 & 0 \\
Total Narrative Ability score & 2 & 2 & 47.5 & 15 \\
\% Grammatical Errors & 40 & 55 & 49.9 & 3.7 \\
\% Content Words & 48 & 51.7 &
\end{tabular}

Table 1 shows simple mean and range for the pre-test I and pre-test II of Phase II, participant I with CI for all measures of the written product. The results show mean $=27$ and range $=4$ for total number of words, mean $=6$ and range $=2$ for total number of sentences, mean $=2$ and range $=0$ for total narrative ability scores because of more use of objects, actions and characters in their narratives, 
mean $=47.5$ and range 15 percent for grammatical errors and mean $=49.9$ and range $=3.7$ for content words showing less sophisticated use of language.

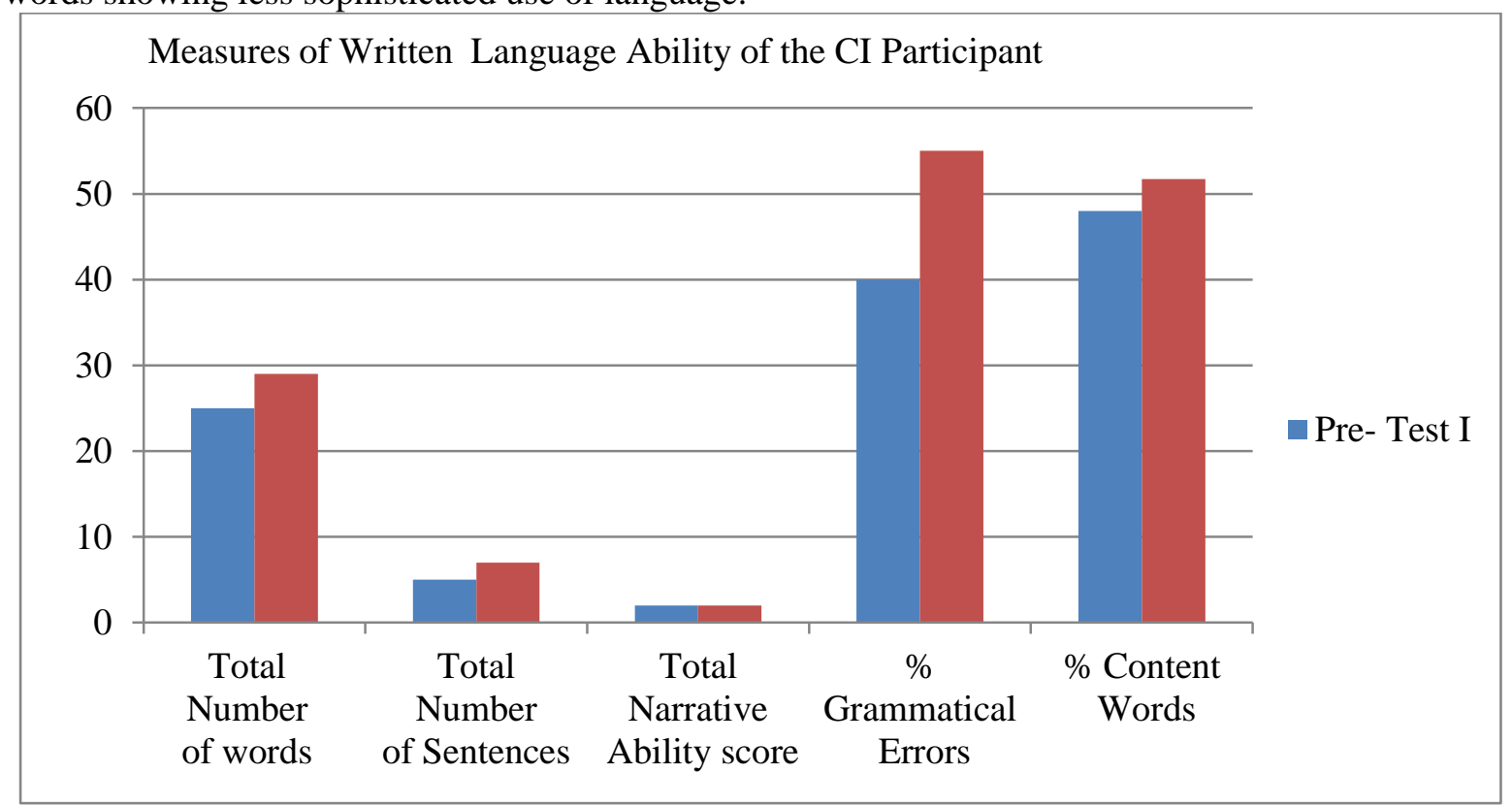

Figure 1. Shows pre-test I and II results on all measures of written language ability of the CI participant.

Table 2

Post-Tests I \& II Results on all Measures of Written Language Ability in the CI Participant

\begin{tabular}{|c|c|c|c|c|}
\hline Measure: Written Product & CI Particip & & & \\
\hline & $\begin{array}{l}\text { Post-Tests } \\
\text { I }\end{array}$ & II & Mean & Range \\
\hline Total Number of words & 127 & 159 & 143 & 32 \\
\hline Total Number of Sentences & 13 & 21 & 17 & 8 \\
\hline Total Narrative Ability score & 10 & 11 & 10.5 & 1 \\
\hline$\%$ Grammatical Errors & 13 & 22.6 & 17.8 & 9.6 \\
\hline$\%$ Content Words & 41.7 & 52 & 46.9 & 10.3 \\
\hline
\end{tabular}

Table 2 shows simple mean and range for the post-test I and post-test II of the participant I with cochlear implant for all measures of the written product. The results show mean $=143$ and range $=32$ for total number of words, mean $=17$ and range $=8$ for total number of sentences, mean $=$ 10.5 and range $=1$ for total narrative ability and mean $=17.8$ and range $=9.6$ percent for grammatical errors and mean $=46.9$ and range $=10.3$ percent for content .

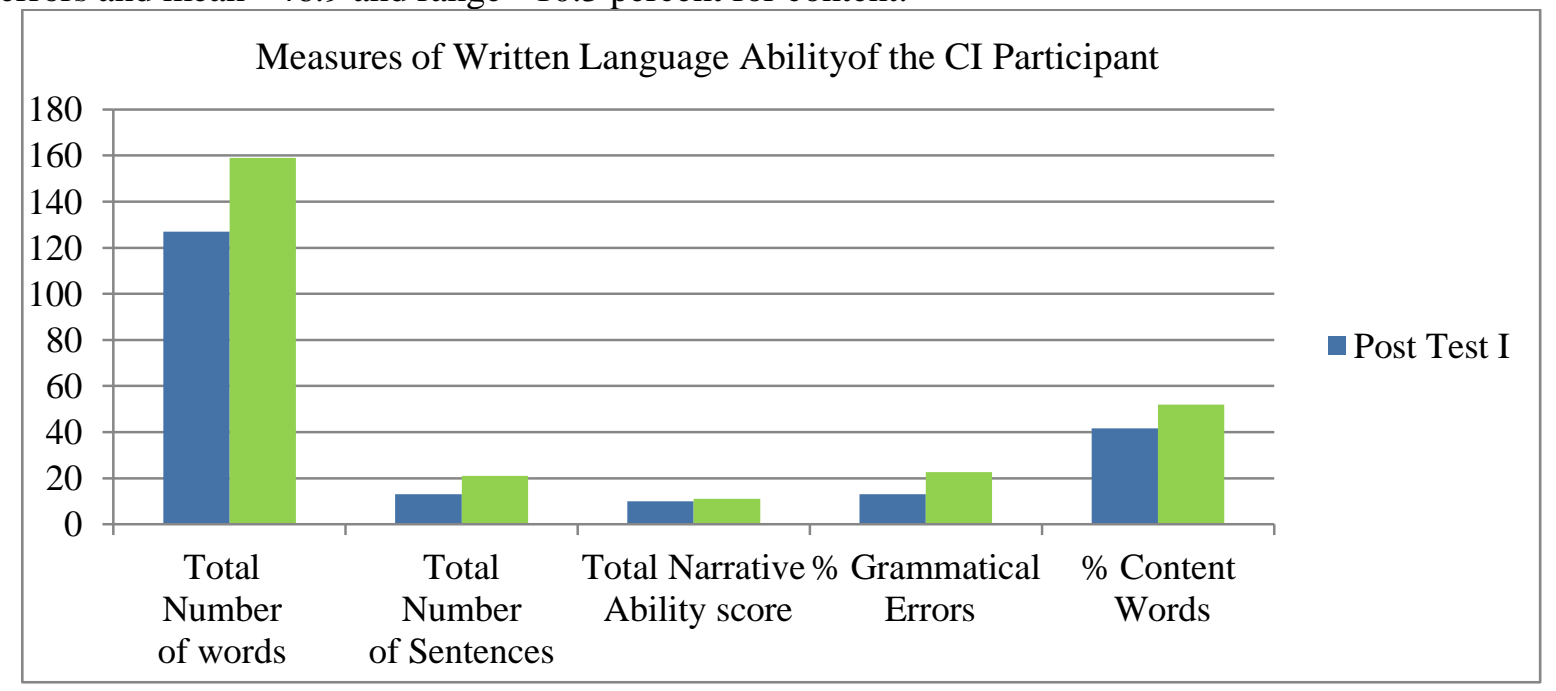


Figure 2. Shows post-test I and II results on all measures of written language ability of the CI participant.

Table 3

Results for Multiple Baselines on all Measures of Written Language Ability in the CI Participant

\begin{tabular}{lllllllll}
\hline Measure: Written Product & \multicolumn{1}{l}{ CI Participant } \\
& \multicolumn{1}{l}{ Sessions } & & & & & & \\
& 1 & 2 & 3 & 4 & Mean & S.D & Median & Range \\
Total Number of words & 94 & 175 & 168 & 159 & 149.0 & 37.2 & 163.5 & 81.0 \\
Total Number of Sentences & 11 & 18 & 23 & 26 & 19.5 & 6.6 & 20.5 & 15.0 \\
Total Narrative Ability score & 11 & 12 & 8 & 11 & 10.5 & 1.7 & 11.0 & 4.0 \\
\% Grammatical Errors & 26.5 & 15.6 & 6.5 & 27 & 18.9 & 9.8 & 21.1 & 20.5 \\
\% Content Words & 50 & 58 & 29.8 & 62 & 50.0 & 14.3 & 54.0 & 32.2 \\
\hline
\end{tabular}

Table 3 shows simple mean, standard deviation, median and range for multiple baselines on all measures of written language ability of the CI participant. Each session comprised of two weeks. The results show descriptive statistics for the four sessions. The mean $=149$, standard deviation $=37.2$, median $=163.5$ and range $=81$ for total number of words. The mean $=19.5$, standard deviation $=6.6$, median $=20.5$ and range $=15$ for total number of sentences. The mean $=10.5$, standard deviation $=1.7$, median $=11$ and range $=4$ for total narrative ability score. The mean $=18.9$, standard deviation $=9.8$, median $=21.1$ and range $=20.5$ for grammatical errors. The mean $=50$, standard deviation $=14.3$, median $=54$ and range $=32.2$ for content words .

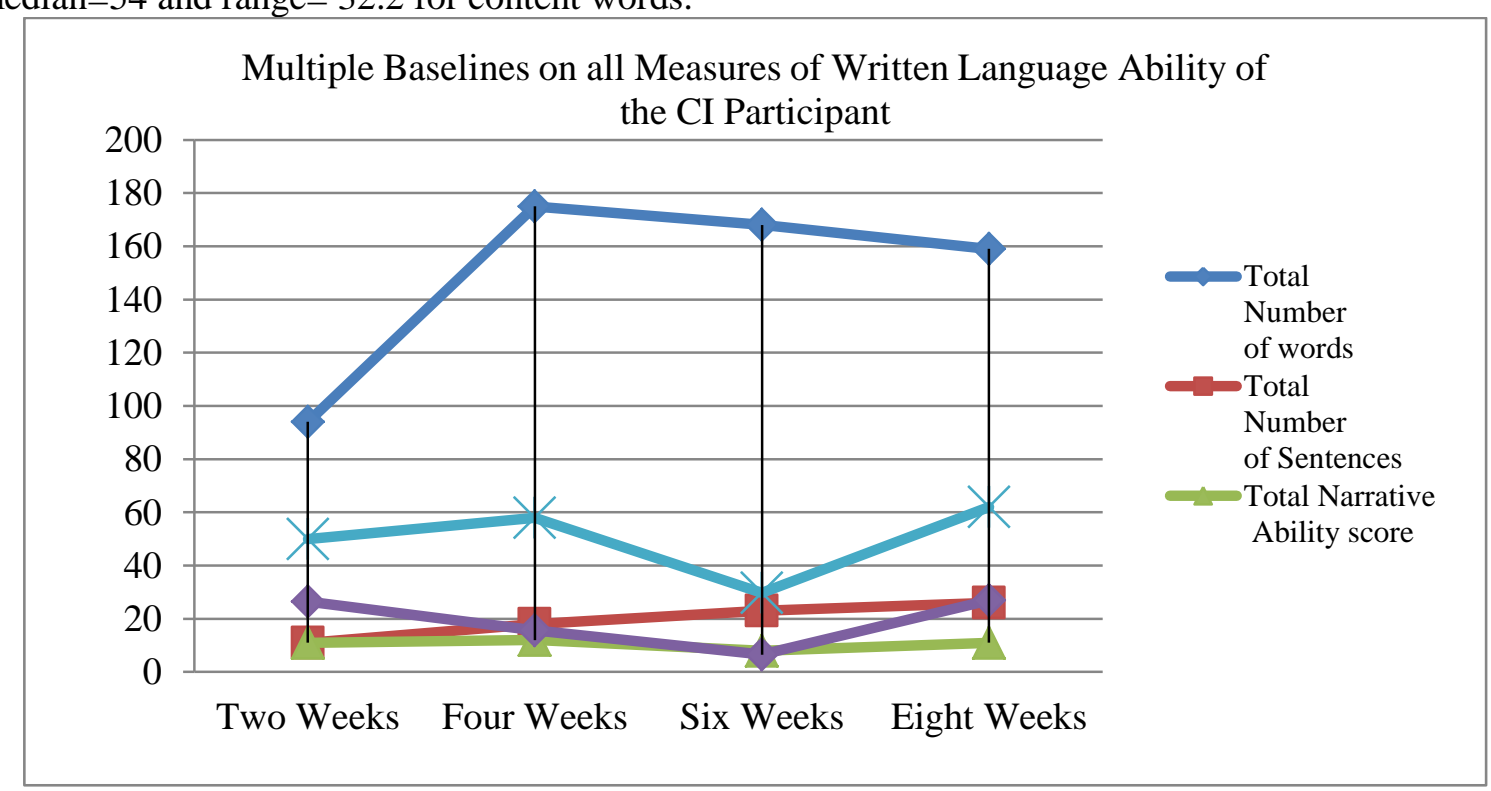

Figure 3.Shows scores on all measures of written language ability of CI participant for all the sessions held during the period of two months.

Table 4

Comparison of Pre-Test I \& Post Test I Results on all Measures of Written Language Ability in the CI Participant

\begin{tabular}{llll}
\hline Measure: Written Product & CI Participant & \\
\hline & Pre-Test I & Post Test I & Diff. \\
Total Number of words & 25 & 127 & 102 \\
Total Number of Sentences & 5 & 13 & 8 \\
Total Narrative Ability score & 2 & 10 & 8 \\
$\%$ Grammatical Errors & 40 & 13 & 27 \\
$\%$ Content Words & 48 & 41.7 & 6.3 \\
\hline
\end{tabular}

Table 4 depicts the comparison between the pre-test I and post- test I for the participant I with cochlear implant of phase II. The comparison shows gain of 102 words, 8 sentences, and 8 narrative ability score. It also shows considerable decrease of $27 \%$ in grammatical errors and $6.3 \%$ decrease in content words. 


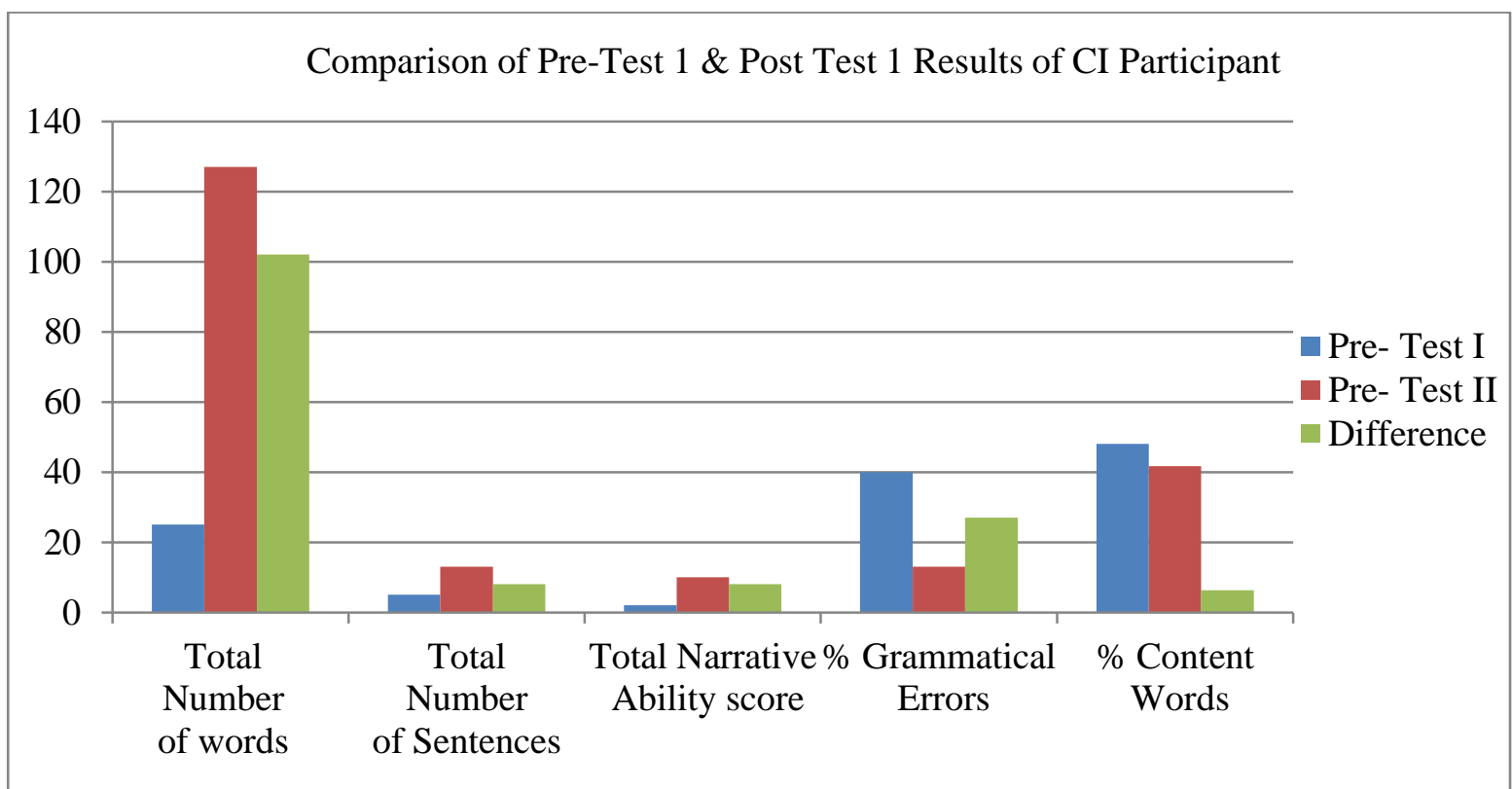

Figure 4. Shows the differences between the pre-test I and post-test I scores on all measures of written language for the CI participant.

Table 5

Comparison of Pre-Test II \&Post Test II Results on all Measures of Written Language Ability in the CI Participant

\begin{tabular}{llll}
\hline Measure: Written Product & CI Participant & & \\
\hline & Pre-Test II & Post Test II & Diff \\
Total Number of words & 29 & 159 & 130 \\
Total Number of Sentences & 7 & 21 & 14 \\
Total Narrative Ability score & 2 & 11 & 9 \\
$\%$ Grammatical Errors & 55 & 22.6 & 32.4 \\
$\%$ Content Words & 51.7 & 52 & 0.3 \\
\hline
\end{tabular}

Table 5 depicts the comparison between the pre-test II and post- test II for the CI participant. The comparison shows gain of 130 words, 14 sentences, and 9 narrative ability score. It also shows considerable decrease of $32.4 \%$ in grammatical errors and minimal decrease of $0.3 \%$ in content words.

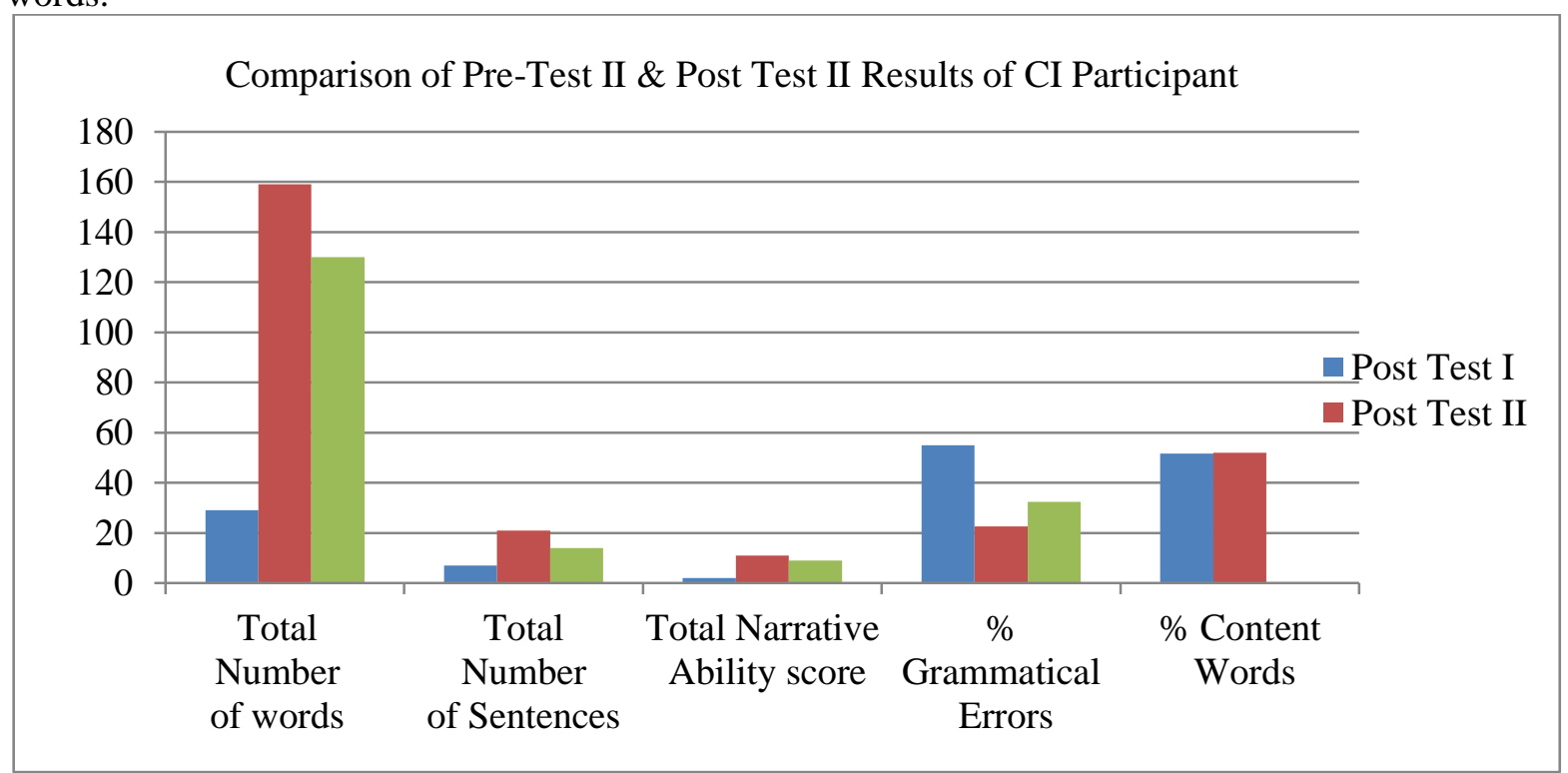

Figure 5. Shows the differences between the pre-test II and post -test II scores on all measures of written language for the CI participant. 


\section{Discussion}

In order to answer proposed research questions, it is important to remember that this study demonstrates that instruction in writing strategies shapes the developmental process in important ways; particularly the structure of the story and structure and development of ideas. CI learners struggle to produce efficient syntactic structured sentences due to difficulties in lower order skills. Studies have associated these difficulties due to deficit in working memory (Bourdin \& Fayol, 1994). This was evident in the participant's pre-tests in which she had constructed simple sentences, however failed to establish a cohesive link between adjacent sentence creating global textual problems. The pre-tests showed poor narrative structure score, a few number of sentences, grammatically incorrect sentences and no subject verb agreement.

The participant before she was given additional intensified auditory input showed that the pretests contained proportionally more orientations. Thus a larger proportion of orientation depicts a predominance of picture descriptions which are very common and irrelevant to resolving problem (Crosson \& Geers, 2001).

The pre-tests depicted a weak plot story with the actions of the characters which do not resolve till the highpoint. She wrote incoherent sentences with no use of connectives, prepositions, pronouns or variation in structure and subject verb agreement error. The stories primarily consisted of descriptions which lacked the characteristics of a true narrative. The pre-test results are in line with previous studies of narratives written by D/HH (Grifth et al., 1990; King \& Quigley 1985; YoshinagoItano \& Snyder, 1985).

The picture storytelling and mind maps aid a writer to structure writing with relative ease, which appeared to be the case for the participant of the research. However, over eight-week intervention period, the participant seemed to develop the Meta cognitive ability to write a narrative with sequential nature and the connecting storyline by causal/temporal connectors, organized her ideas coherently. She added small sentences about the pictures and commented on them more often. Initially her stories had either incorrect or no beginning at all. She used simple words and mentioned the setting unclearly and could not put the words in proper order. Gradually, she began adding the main ideas, used supporting ideas and defined setting. By the eighth week, she began to form compound sentences, new words but made a few grammatical errors. The increasing interest was visible in her picture conversation. She used conjunctions and prepositions which she had definitely learned through recasting. This was evident when comparisons were drawn between her pre and postwriting samples. These results are in line with the study conducted by Alidiost et al. (2014).

Writing also involves the cognitive component working memory. Paivio's (2007) cognitive model is based on the use of videos and picture to make story telling more imaginative. This method teaches vocabulary, syntactic structure, use of connectors and prepositions. His dual coding theory, supports the learners input of new ideas by presenting visual imagery.

Paivio (2007) holds that the verbal and nonverbal information is processed in the brain via two systems which support each other and result in efficient recall. These systems become interconnected and learners recall the story differently and better when children are introduced words and visual images together or in close proximity which helps in maintaining the concepts in working memory (Baddeley 1998).

The picture telling story telling through read aloud has the potential of giving access to children to simultaneous instruction. The use of several modalities such as videos, text tracking, pictures and the story both heard and seen simultaneously reduce cognitive load. The participant struggled with memory difficulties, a deficit expressed by the participant. Despite being able to annotate good ideas verbally she was unable to remember these ideas long enough to express them in written form. As stated by the participant in her pre interview "All my ideas are jumbled up" which was evident in the pre writing samples. Picture storytelling and mind maps gave her a visual framework to express her ideas and subsequently refer back to when memory failed.

Mind maps helped the participant construct a number of paragraphs by showing her that each main branch along with its subsidiary branches was the start of a new paragraph. This understanding helped develop and structure the written product: a difficulty expressed in the interview by the participant. Bourdin and Fayol (1994) investigated the relationship between cognitive overload and transcription process in second and fourth graders. They concluded that children experienced more 
writing difficulties due to less efficient processing of lower level writing skills, hence placing great demands on working memory.

Keeping in mind the importance of planning and reviewing as advocated by Flower and Hayes (1981) the participant was taught to tick each idea on her mind map after it was expressed. This reduced cognitive overload and memory difficulties. After the construction of a written text each the construction of written text the participant reviewed her work to look for errors in the mechanics (Young, 2000) of writing and to cross check whether all the idea generated in mind maps had been included. Mind maps also helped the participant to find a clear purpose and focus, generate and organize related ideas, start a new paragraph and recalling ideas. As stated by the participant that she enjoyed and liked all the sessions of storytelling especially the retell session and sketching of mind maps. As said by the participant that she loved to tell stories.

After receiving the extensive auditory exposure during the intervention phase, her post- test reflected evaluation, orientation, conjunction linked to semantic relation in the stories. Syntactic knowledge helps construct cohesion in a narrative. The participant's post writing sample showed good use conjunctions and comma like in the last sentence "She told him, we should not play with strangers so he did not played with boy and came back." She used number of adjectives to make her writing interesting e.g. little boy, strange boy, good boy beautiful park. The intervention in the study showed the use of conjunctions in narratives helped the learners to join sentences (Snow et al., 1990). In the later sessions, the participant demonstrated lesser errors in grammar, parts of speech and verb conjugation. These findings affirm that of Kara, Aydin \& Cagiltay (2013) according to which cognitive development enhances through storytelling. The writing sample showed appropriate and interesting content with consistent use of full stops, capital letters appropriate use of pronouns, less grammatical errors and good adjectives. It was interesting to note that in her sentences she had used conjunctions more effectively. The appropriate use of pronouns, subject verb agreement was seen, the difficulty which was noted in her first pre-writing sample. All paragraphs followed a logical sequence with relevant, interesting and cohesive ideas to engage the reader. She used appropriate yet simple vocabulary that was limited in range. She mostly used simple or compound sentences, which showed some variation; extended by the use of limited connectives. The Mind Map she drew a detailed one. This Mind Map was different from all the other Mind Maps that she had created. She constructed the framework of the Mind Map confidently. It has further been advocated by the school of research, which focuses the intellectual and pragmatic enhancement, when storytelling takes place cognition improves (Harriot \& Martin, 2004; Sima \& Cordi, 2003).

The post-tests depicted that $\mathrm{C} 1$ used temporal conjunctions and helped in the temporal ordering of the events. However, the post tests showed fewer causal conjunctions which reflect a lack of linguistic maturity rather than a lack of understanding of cause effect relation (Crosson \& Geers, 2001). The use of intense exposure and intervention brought forward fruitful effect on narrative writing. A comparison between post-test and pre-test showed that the student benefited from the extensive auditory exposure.

\section{Conclusion}

The overall findings show that picture storytelling and mind maps proved to be an effective tool used to aid a cochlear implanted learner's progress in her writing. These findings highlight the desperate need for teachers and educators to use picture storytelling and mind maps in educational settings. However, in order to use them effectively, teachers must understand the cognitive processes that contribute to cochlear implanted learner's writing ability and the role that picture storytelling and mind maps play in supporting these cognitive processes.

\section{References}

Alidoost, Y., Tabatabaei, S., \& Bakhtiarvand, M. (2014). The effect of picture story in creating textual coherence in narrative genre. Theory and Practice in Language Studies, 4(2), 359-365.

Arfé, B., Nicolini, F., \& Pozzebon, E. (2014).The influence of verbal working memory on writing skills in children with hearing loss. In Arfé B, Dockrell J, Berninger WV, editors. Writing development in children with hearing loss, dyslexia or oral language problems: implications for assessment and instruction. New York, NY: Oxford University Press; p. 8599. 
Bamberg, M., \& Damrad-Frye, R. (1991). On the ability to provide evaluative comments: further explanations of children's narrative competencies. Journal of Child Language, 18, 689-710.

Berman, R. A. (1996). Form and Function in Developing Narrative Abilities. In Social Interaction, Social Context, and Language: Essays in Honor of Suzan Ervin-Tripp, edited by Slobin, D.I., Gerhardt, J., Kyratziz, A., Guo, J. 343-368. Hillsdale, NJ: Erlbaum.

Blamey, P. J., Sarant, J.Z., Paatsch, L.E., Barry, J.G., Bow, C.P., (2001). Relationships among speech perception, production, language, hearing loss, and age in children with impaired hearing. Journal of Speech Language Hearing and Research, 44:264-285.

Bourdin, B. \&Fayol, M. (1994). Is written language production more difficult than oral language production? A working memory approach. International Journal of Psychology, 29, 591-620.

Buzan, T. (2006) Use your head: Innovative Learning and Thinking Techniques to Fulfil Your Potential: New Ed. London: BBC (BBC Active).

Crosson, J., \& Geers, A. (2001). Analysis of narrative ability in children with cochlear implants. Ear and Hearing, 22(5), 381-394. Doi: 10.1097/00003446-200110000-0000.

David, P. (1998). News concreteness and visual-verbal association: Do news pictures narrow the recall gap between concrete and abstract news? Human Communication Research, 25(2), 180201.

Flower, L. \& Hayes, J.R. (1981).A Cognitive Process Theory of Writing. College Composition and Communication, 32 (4), 365-87.

Griffith, P. L., Ripich, D. N., \&Dastoli, S. L. (1990). Narrative abilities in hearing- impaired children: Propositions and cohesion. American Annals of the Deaf, 135, 14-19.

Harriott, W.A., \& Martin, S.S. (2004).Using culturally responsive activities to promote social competence and classroom community. Teaching Exceptional Children, 37 (1), 48-54.

Kara, N., Aydin, C.C., \&Cagiltay, K. (2013).Investigating the Activities of Children toward a Smart Storytelling Toy. Educational Technology \& Society, 16, 28-43.

Kemmis, S. (2009). Action research as a practice-based practice. Educational Action Research, 17(3), $463-474$.

Kemmis, S., McTaggart, R., \&Retallick, J. (Eds.). (2004). The action research planner (2nd ed.). Karachi, Pakistan: Aga Khan University Institute for Educational Development.

Khan, M.I. J., Mukhtar, N., Saeed, S.R. \&Ramsden, R. T. (2007). The Pakistan (Lahore) cochlear implant programme: issues relating to implantation in a developing country. The Journal of Laryngology \& Otology, 121,745-750. \# 2007 JLO (1984) Limited doi: 10.1017/S0022215107007463.

King, C. M., \& Quigley, S. P. (1985).Reading and deafness. San Diego, CA: College-Hill Press.

Labov, W., \&Waletzky, J. (1967).Narrative analysis. In J. Helm, Essays on the verbal and visual arts (pp.12-44). Seattle: Washington Press.

Moog, J.S. (2002). Changing expectation for children with cochlear implants. The Annals of Otology, Rhinology \& Laryngology, 189 (supplement), 138-142.

Nicholas, J.G. \&Geers, A. E. (2007). Will They Catch up? The Role of Age at Cochlear Implantation in the Spoken Language Development of Children with Severe to Profound Hearing Loss. Journal of Speech, Language and Hearing Research, 50:1048-62.

Paivio, A. (2007). Mind and its evolution: A dual coding theoretical approach. Lawrence Erlbaum Associates Publishers.

Payne, T., \& Turner, E. (1999). Dyslexia: A parents' and teachers' guide. Clevedon, North Somerset, UK: Multilingual Matters.Raimes, A., (1983). Techniques in Teaching Writing. New York: Oxford University Press.

Schopmeyer, B., Mellon, N., Dobaj, H., Grant, G., \&Niparko, J. K. (2000).Use of Fast For Word to enhance language development in children with cochlear implants. The Annals of Otology, Rhinology, and Laryngology, 185, 95-98.

Sima, J., \& K. Cordi. (2003). Raising Voices: Creating youth storytelling groups and troupes. Westport, CT: Libraries Unlimited.

Spencer, L., Barker, B. \& Tomblin, J. B. (2003). Exploring the Language and Literacy Outcomes of Pediatric Cochlear Implant Users. Ear and Hearing, 24(3): $236-47 . x t=$ utk_theopubs], Retrieved on December 21, 2016. 
Snow, C. E., \& Dickinson, D. K. (1990).Social sources of narrative skills at home and at school. First Language, 10, 87-103.

Wu, C. M., Ko, H. C., Chen, Y. A., Tsou, Y. T., \& Chao, W. C. (2015). Written Language Ability in Mandarin-Speaking Children with Cochlear implants. BioMed Research International, 2015, 282164. doi: $10.1155 / 2015 / 282164$

Yoshinaga-Itano, C. \& Snyder, L.S. (1985). Form and meaning in the written language of hearingimpaired children. The Volta Review, 87, 63-96.

Young, D.J. (2008). The Mechanics of Writing: Which comes first the, the comma or the pause? Writers Toolkit Publishing LLC, 1-15.

Yoshinaga-Itano, C., \& Downey, D. (1992). When a story is not a story: A process analysis of the written language of hearing-impaired children. The Volta Review, 95, 131-158. 